\title{
The Spatial Effect of Venture Capital on Green Technology Innovation-Empirical Research Based on Inter-Provincial Panel Data
}

\author{
Cuiping Niu, Yanwen Shui*, Xianmin Zhang \\ Anhui University of Finance and Economics, Bengbu, China \\ Email: ${ }^{\star} 1633503204 @ q q . c o m$
}

How to cite this paper: Niu, C.P., Shui, Y.W. and Zhang, X.M. (2022) The Spatial Effect of Venture Capital on Green Technology Innovation-Empirical Research Based on Inter-Provincial Panel Data. Open Access Library Journal, 9: e8316.

https://doi.org/10.4236/oalib.1108316

Received: December 21, 2021

Accepted: January 11, 2022

Published: January 14, 2022

Copyright $\odot 2022$ by author(s) and Open Access Library Inc.

This work is licensed under the Creative Commons Attribution International License (CC BY 4.0).

http://creativecommons.org/licenses/by/4.0/

\begin{abstract}
Venture capital, as an active financing method, has introduced many noncapitalized services while providing funds. Green technological innovation, as an important force in promoting the green and ecologicalization of China's industrial structure, has an impact on the relationship between the two analyses is necessary. This paper explores the relationship between green technology innovation and venture capital through panel data from various regions of China (except Hong Kong, Macao, Taiwan and Tibet) from 2001 to 2019 by constructing a common panel model and a spatial panel model. Research shows that: 1) Venture investment has a positive impact on green technology innovation, and there is a spatial effect, that is, venture capital in surrounding areas has a positive impact on green technology innovation in the region; 2) The level of technology investment, the level of opening up and the intensity of environmental regulations have all impacts on green technology innovation. It has a positive impact; 3) Considering the influence of surrounding areas, the level of government intervention has a negative impact on green technology innovation in the region. Therefore, it is necessary to continue to increase investment in the future and at the same time adopt corresponding measures in technology investment, especially government policy intervention, in order to optimize China's green technology innovation level in multiple dimensions.
\end{abstract}

\section{Subject Areas}

Business Finance and Investment

\section{Keywords}

Venture Capital, Green Technological Innovation, Panel Model, Spatial Effect 


\section{Introduction}

In the past 30 years, China's economic construction has achieved rapid development. The total GDP has increased from 367.87 billion yuan in 1978 to 101.60 trillion yuan in 2020. The serious consumption of resources has led to China's economic growth showing "high growth and high energy". The characteristics of high consumption and high pollution, and the "black troubles" have also become factors hindering the sustainable development of China's economy. In 1972, Meadows mentioned in the book "The Limits of Growth" that "the danger of ecological limits can be avoided through technological innovation, and technological progress will play an important role in the coordinated development of economic growth and resources and the environment." Because green technology innovation plays a positive role in reducing environmental pollution, reducing energy consumption, and improving the supply of ecological technology and industrialization, it has gradually attracted the attention of those in power. In recent years, China has issued various policies and guidelines to promote the development of green technology innovation. For example, in April 2019, the National Development and Reform Commission of China and the Ministry of Science and Technology jointly issued a document on the establishment of a market-oriented green technology innovation mechanism. In addition, as an important financing method for high-tech start-ups, venture capital can not only provide financial support for technological innovation, but also introduce many non-capitalized value-added services. In 2020, the scale of China's venture capital investment reached 991.012 billion yuan, and its compound growth rate in the past ten years was as high as $14.07 \%$, demonstrating the strong vitality of China's venture capital market. At present, China's internal R \& D expenditures account for a relatively low proportion of GDP, with an average of less than $2 \%$, which is quite different from developed countries.

Therefore, it is necessary to continue to increase the scale of technology investment, support the development of strategic green technological innovation industries, and release industrial dividends in advance. Improve the independent ability of green technology innovation, further accelerate the process of industrial ecologicalization and reserve more technologies. The research structures are as follows: Firstly, we conduct the literature review and establish hypotheses; secondly, we select Variables and design models; thirdly, we analyze and discuss empirical results; finally, we draw conclusions and provide some suggestions from the government's perspective. When formulating corresponding development policies, governments at all levels in China need to focus on matching and coordinating with other policies, so as to leverage the spillover effect of venture capital on green technology innovation. Maintain a unified level to play the role of environmental regulations. And study the relationship between venture capital and green technology innovation, and analyze whether the former can be one of the driving forces of green innovation. It is related to the choice of government policy making and development decision-making, which has strong theo- 
retical and practical significance.

\section{Literature Review and Hypotheses}

At present, the academic circles have not yet established a unified understanding of the relationship between venture capital and green technology innovation. Most studies have pointed out that there is a typical positive relationship between the two, and some scholars have found that venture capital has an effect on green technology innovation through empirical analysis. The impact is not significant or even negative. There are two research hypotheses in the paper. The following will be described from two aspects.

Lerner [1] took the manufacturing industry from 1965 to 1992 in the United States as the research object, and found that venture capital can increase the number of patent applications and thus continuously improve technological innovation capabilities; Tykvova [2] analyzed the data of German companies and found that venture capital investment Technological innovation has a significant positive effect; Pradhan [3] studied the relationship between venture capital and innovation in 19 European countries from 1989 to 2014, and found that there is a two-way and one-way relationship between the two, that is, risk Investment can effectively promote technological innovation, and technological innovation can also affect venture capital; Sun [4] builds a regression equation through Chinese corporate panel data, and concludes that corporate innovation performance is significantly affected by venture capital; Yan Fafa [5] builds a VECM model Analyzed the balanced relationship between venture capital and technological innovation, and concluded that venture capital promotes technological innovation in both the long-term and short-term; Wang Xinxin [6] uses the 2005-2019 inter-provincial panel data to construct the return of venture capital and green technology innovation. The model shows that venture capital can effectively promote China's green technology innovation. On the basis of the above, the basic research hypothesis of this article is proposed:

H1: Venture capital has a positive impact on green technology innovation.

Chen Zhi [7] used the Malmquist index to find that China's venture capital clusters (such as Beijing, Jiangsu, etc.) are more efficient in technological innovation than non-aggregated regions (such as Fujian); Xu Daiting [8] through innovative production Function analysis shows that venture capital has a significant role in promoting technological development and innovation in eastern China, but not in the central and western regions, showing a negative impact; Yao Li [9] uses inter-provincial panel information from 2006 to 2015 to construct risk The spatial measurement model of investment level and regional technological innovation shows that venture capital has a significant spatial spillover effect on technological innovation; Wen et al. [10] used the venture capital and technological innovation data of 28 provinces in China from 2001 to 2014 to construct a PSTR model, It is concluded that venture capital has a re- 
straining effect on technological innovation in western China; Zhang Yongkai [11] innovatively uses Kortum and Lerner's patent output function, and the study found that venture capital has the most significant role in promoting technological innovation in eastern China. Based on this, research hypothesis 2 is proposed:

\section{H2: Venture capital has spatial effects.}

\section{Variable Selection and Model Design}

\subsection{Variable Selection}

\subsubsection{Explained Variables}

At present, Green Technology Innovation (GT), the Chinese academic community has not yet formed a unified understanding of the measurement of this indicator. Based on the availability and representativeness of the data, it draws on the research conclusions of Liu [12] and Wang [13] and adopts the number of green patents in a certain year (green inventions). The ratio of patents and green utility model patents to the total number of green patents in China in a certain year is used as a measure.

\subsubsection{Explaining Variables}

Because of the research on whether there is a spatial effect of venture capital on green technology innovation and how the effect is, the measurement indicators of venture capital (VC) in previous studies are generally the amount of initial investment funds, the number and amount of venture capital projects. Based on the availability and accuracy of data, this paper uses the ratio of the amount of regional venture capital investment (100 million yuan) to the total amount of national venture capital in a certain year as the measurement index.

\subsubsection{Control Variables}

The selection of control variables should include variables that can affect green technology innovation through influencing venture capital. Based on the research of Cheng Du [14] and Jiang Hanming [15], four indicators are selected: technology investment level, opening-up level, government intervention level, and environmental regulation intensity. Technology investment level (R\&D) is one of the core driving forces of technological innovation, and has a strong guiding role in technological innovation. This article uses the ratio of regional $\mathrm{R} \& \mathrm{D}$ expenditure (100 million yuan) to GDP (100 million yuan) to measure the level of technology investment (RD); The level of opening to the outside world (OPEN), which mainly includes foreign direct investment and international trade, has a positive effect on regional innovation through external effects such as potential "learning by doing" and technology diffusion.

This article uses foreign direct investment (100 million yuan) and The ratio of total import and export trade (100 million yuan) to GDP (100 million yuan) in the same period is used as a measure of the level of openness; government intervention (GOV) reflects the degree of government dominance over the economy, 
and the local government competition system under "Chinese-style decentralization". As a result, government actions will inevitably have an important impact on the direction and development of technological innovation, measured by the general government budget expenditure ( 100 million yuan) in the proportion of GDP (100 million yuan) in the same period; environmental regulation (EA), that is, the intensity of government supervision of enterprises, which makes enterprises forced For environmental protection investment, technological innovation and other activities, this article uses the ratio of the number of environmental administrative punishment cases accepted in a certain year to the total number of punishment cases nationwide in a certain year.

\subsection{Model Design}

It can be seen from the literature review that because venture capital may have a spatial spillover effect on green technology innovation, the common panel model cannot measure its lag effect, and it is easy to cause estimation bias. Therefore, this paper constructs the ordinary panel model and the spatial panel model respectively in order to obtain different estimation effects. First, build a common panel model, as shown in (1).

$$
G T_{i, t}=\alpha+\rho_{1} V C_{i, t}+\rho_{2} R D_{i, t}+\rho_{3} O P E N_{i, t}+\rho_{4} G O V_{i, t}+\rho_{5} E A_{i, t}+\varepsilon_{i, t}
$$

Among them, $i$ represents the region, $t$ represents the year. $\rho_{1}-\rho_{5}$ represents the variable regression coefficient; $\varepsilon_{i, t}$ represents the random disturbance item.

Secondly, construct a spatial panel model. In order to analyze the impact of venture capital on green technology innovation, construct a spatial autoregressive model (SAR), a spatial error model (SEM) and a spatial Dubin model (SDM).

Where $X_{\varphi, i t}=\rho_{1} V C_{i, t}+\rho_{2} R D_{i, t}+\rho_{3} O P E N_{i, t}+\rho_{4} G O V_{i, t}+\rho_{5} E A_{i, t}$.

First, spatial autoregressive model.

$$
G T_{i t}=\beta_{0}+\sum_{\varphi=1}^{n} \beta_{\varphi} X_{\varphi, i t}+\tau w_{i j} * G T_{i t}+\varepsilon_{i t}
$$

Among them, $w_{i j}$ is the spatial weight matrix, $w_{i j} * G T_{i t}$ is the spatial lag variable of the dependent variable, and $\tau$ is the spatial regression coefficient, which reflects the direction and degree of the influence of the observable value in the adjacent region of $i$ region on the venture capital in this region.

Second, spatial error model.

$$
G T_{i t}=\beta_{0}+\sum_{\varphi=1}^{n} \beta_{\varphi} X_{\varphi, i t}+\tau w_{i j} * \varepsilon_{i t}+\varphi_{i t}
$$

Among them, $w_{i j}$ is the spatial weight matrix, $w_{i j} * \varepsilon_{i t}$ is the spatial lag error term, and $\tau$ is the spatial regression coefficient, which reflects the direction and degree of the unobservable influence factors or random shocks in the adjacent region of $i$ region on the venture capital in this region.

Third, spatial Durbin model.

$$
G T_{i t}=\beta_{0}+\sum_{\varphi=1}^{n} \beta_{\varphi} X_{\varphi, i t}+\tau w_{i j} * G T_{i t}+\mu w_{i j} * \sum_{\varphi=1}^{n} X_{\varphi, i t}+\varepsilon_{i t}
$$


Among them, $w_{i j}$ is the spatial weight matrix, $w_{i j} * G T_{i t}$ is the spatial lag variable of the dependent variable, $w_{i j} * X_{\varphi, i t}$ is the spatial lag variable of the explanatory variable, and the spatial Durbin model also examines the impact of venture capital in adjacent region on the region and the impact of factors or random shocks in adjacent region on venture capital in this region.

\subsection{Spatial Weight Matrix}

Spatial weight matrix is a necessary part of spatial econometric analysis. In order to prevent prior errors caused by the construction of spatial weight matrix, this article will construct two types of spatial weight matrix and conduct in-depth analysis of the empirical results, namely geographic distance matrix $W D_{i j}$ and economic matrix $W E_{i j}$. The following is the specific calculation formula for each matrix:

1) 0 - 1 spatial weight matrix WG. If the two regions are geographically adjacent, it is recorded as 1 ; if they are not adjacent, it is recorded as $0 . d_{0}$ is the threshold of different radius, reflecting the significance of the spatial spillover effect within different radiuses.

$$
W G_{i j}= \begin{cases}W=1 / d_{i j}, & d_{i j} \leq d_{0} \\ W=0, & d_{i j}>d_{0}\end{cases}
$$

2) Geographic distance matrix WD. $d_{i j}$ is the geographic distance between provinces $i$ and $j$, measured by the shortest railway mileage between the corresponding provincial capitals.

$$
W D_{i j}=\left(1 / d_{i j}\right) /\left[\sum_{j=1}^{N}\left(1 / d_{i j}\right)\right]
$$

In this paper, the spatial panel model will use the WE matrix, and the robustness test will use the WD matrix.

\section{Empirical Analysis and Discussion}

\subsection{Data Sources and Descriptive Statistics}

Select panel data from various regions of China (except Hong Kong, Macao, Taiwan and Tibet) from 2001 to 2019 to analyze the relationship between China's venture capital and green technology innovation. The data comes from "China Statistical Yearbook", "China Science and Technology Statistical Yearbook", wind data terminal and authoritative data published by various regions. The descriptive statistics of each variable are shown in Table 1.

\subsection{Empirical Results}

\section{Model Test Results}

The results of the Hausman test of the risk investment regression show that the $\mathrm{P}$ values are all significant at the $1 \%$ level, rejecting the assumption of no difference between fixed effects and random effects estimates. At the same time, the fixed effects model has the best effect. Therefore, this paper adopts the fixed 
Table 1. Variable descriptive statistics.

\begin{tabular}{cccccccc}
\hline Variable & Abbrew & Obs & Mean & Std. Dev. & Min & Max \\
\hline Green technological innovation & GT & 570 & 0.033 & 0.036 & 0 & 0.159 \\
risk investment & VC & 570 & 0.006 & 0.023 & 0 & 0.234 \\
Level of investment in technology & RD & 570 & 0.011 & 0.01 & 0 & 0.06 \\
Level of opening to the outside world & OPEN & 570 & 0.212 & 0.097 & 0.03 & 0.628 \\
Level of government intervention & GOV & 570 & 0.033 & 0.046 & 0 & 0.334 \\
Environmental regulation intensity & EA & 570 & 9.013 & 1.596 & 6.04 & 15.451 \\
\hline
\end{tabular}

effects model to carry out the measurement model. Construct. It can be seen from Table 2 that the fit degree of green technology innovation estimated by OLS is 0.561 , which passes the significance test at the $1 \%$ level as a whole. In order to further analyze the spatial effect of regional venture capital on green technology innovation, this paper uses the lag term to construct a spatial measurement model to analyze it. The analysis results show that the green technology innovation fit degree estimated by SAR, SEM and SDM are 0.528, 0.527 and 0.669 respectively. By comparing the Log-L of the three models, it is concluded that the SDM model has a better fitting effect. At the same time, the rho value of SAR and the Lambda value of SEM are significantly positive, indicating that the spatial dependence of green technology innovation is very significant, that is, the regional green technology innovation will be affected by the synergistic effect of green technology innovation in the surrounding area, and the innovation level of the region will be enhanced.

It can be seen from Table 2 that the influence coefficients of VC on GT in the OLS, SAR, SEM and SDM models are 0.221, 0.065, 0.042 and 0.138 respectively, and are significant in the OLS and SDM models, indicating that venture capital has a positive effect on green technology innovation. Promotional effect, suppose $\mathrm{H} 1$ holds. It can be seen from the SDM model that $\mathrm{W}^{\star} \mathrm{VC}$ is significantly positive for GT, indicating that venture capital has a spatial effect. Hypothesis $\mathrm{H} 2$ is established, that is, green technology innovation in this region will be positively affected by venture capital in neighboring areas. The "spatial club" feature is consistent with the research of Qiao Qin et al. [16], which means that the region can coordinate with neighboring regions to formulate favorable policies to increase the level of venture capital, thereby promoting regional green technology innovation.

Various control variables such as RD, OPEN, GOV have different effects on green technology innovation. Technology investment level (RD) has a significant positive impact on green technology innovation, and the variable coefficients are the highest among all independent variables (all above 1.5), indicating that China's current green technology innovation mainly relies on the direct guidance of technology investment. The level of opening to the outside world (OPEN) has a positive effect on green technology innovation, indicating that the higher the 
Table 2. Regression results of panel model.

\begin{tabular}{|c|c|c|c|c|}
\hline Variables & OLS & SAR & SEM & SDM \\
\hline $\mathrm{VC}$ & $\begin{array}{l}0.221^{\star * *} \\
(0.009)\end{array}$ & $\begin{array}{c}0.065 \\
(0.135)\end{array}$ & $\begin{array}{c}0.042 \\
(0.403)\end{array}$ & $\begin{array}{c}0.138^{\star * *} \\
(0.001)\end{array}$ \\
\hline $\mathrm{RD}$ & $\begin{array}{c}1.673^{\star * *} \\
(0.000)\end{array}$ & $\begin{array}{c}1.754^{\star * *} \\
(0.000)\end{array}$ & $\begin{array}{c}1.945^{\star * *} \\
(0.000)\end{array}$ & $\begin{array}{c}1.513^{\star * *} \\
(0.000)\end{array}$ \\
\hline OPEN & $\begin{array}{c}0.210^{\star * *} \\
(0.000)\end{array}$ & $\begin{array}{l}0.079^{\star *} \\
(0.030)\end{array}$ & $\begin{array}{c}0.136^{\star * *} \\
(0.001)\end{array}$ & $\begin{array}{c}0.024 \\
(0.483)\end{array}$ \\
\hline GOV & $\begin{array}{l}0.025^{\star *} \\
(0.019)\end{array}$ & $\begin{array}{c}-0.009^{* * *} \\
(0.000)\end{array}$ & $\begin{array}{l}-0.014 \\
(0.328)\end{array}$ & $\begin{array}{l}-0.003 \\
(0.811)\end{array}$ \\
\hline EA & $\begin{array}{c}0.297^{\star * *} \\
(0.000)\end{array}$ & $\begin{array}{c}0.224^{\star * *} \\
(0.000)\end{array}$ & $\begin{array}{c}0.242^{\star * *} \\
(0.000)\end{array}$ & $\begin{array}{c}0.198^{\star * \star} \\
(0.000)\end{array}$ \\
\hline $\mathrm{W}^{\star} \mathrm{VC}$ & & & & $\begin{array}{c}0.823^{\star * *} \\
(0.000)\end{array}$ \\
\hline $\mathrm{W}^{\star} \mathrm{RD}$ & & & & $\begin{array}{c}1.046^{* * *} \\
(0.000)\end{array}$ \\
\hline $\mathrm{W}^{\star} \mathrm{OPEN}$ & & & & $\begin{array}{c}0.605^{\star * *} \\
(0.000)\end{array}$ \\
\hline $\mathrm{W}^{\star} \mathrm{GOV}$ & & & & $\begin{array}{c}0.008 \\
(0.831)\end{array}$ \\
\hline $\mathrm{W}^{*} \mathrm{EA}$ & & & & $\begin{array}{c}0.241^{\star * *} \\
(0.000)\end{array}$ \\
\hline Constant & $\begin{array}{c}-0.007^{\star *} \\
(0.017)\end{array}$ & & & \\
\hline Lambda & & & $\begin{array}{c}0.349^{* * *} \\
(0.000)\end{array}$ & \\
\hline rho & & $\begin{array}{c}0.451^{\star * *} \\
(0.000)\end{array}$ & & $\begin{array}{l}-0.052 \\
(0.460)\end{array}$ \\
\hline sigma2_e & & $\begin{array}{c}0.000^{\star * *} \\
(0.000)\end{array}$ & $\begin{array}{c}0.000^{* * *} \\
(0.000)\end{array}$ & $\begin{array}{c}0.000^{\star * *} \\
(0.000)\end{array}$ \\
\hline Observations & 570 & 570 & 570 & 570 \\
\hline R-squared & 0.561 & 0.528 & 0.527 & 0.669 \\
\hline F-test & 144.389 & & & \\
\hline Prob $>$ F & 0.000 & & & \\
\hline Log-likelihood & & 1395.6397 & 1359.0024 & 1459.8987 \\
\hline
\end{tabular}

Remarks: ${ }^{* *} \mathrm{p}<0.01,{ }^{* *} \mathrm{p}<0.05,{ }^{\star} \mathrm{p}<0.1$.

level of a region's openness to the outside world, the stronger its ability to attract venture capital, and the degree of openness in surrounding areas positively affects the level of green technology innovation in the region. The level of government intervention (GOV) in the OLS regression has a significant positive impact on green technology innovation, while it is negative and insignificant in 
the spatial panel model, indicating that the ordinary panel model has estimation errors without considering the level of government intervention in surrounding areas. From the SAR, SEM, and SDM models, it can be seen that the stronger the level of government intervention has a negative impact on the region's green technology innovation, indicating that the current Chinese government intervention has a certain degree of blindness. The intensity of environmental regulation (EA) has a significant positive impact on green technology innovation, and because government behavior has no time lag or anticipation compared to corporate behavior, the higher the intensity of environmental regulation, the stronger the restriction on the development of high-polluting technologies. The development of green technology provides an opportunity. In addition, government actions can speed up the flow of capital market funds from high-polluting industries to green industries, enabling more green and innovative enterprises to obtain financial support, and further promote green technological innovation.

\subsection{Robust Inspection}

In order to ensure the reliability of the conclusions of this article, combined with the premises and assumptions that this article focuses on data processing rather than the establishment of the research method, the reduced window method is adopted for the ordinary panel model, that is, the data from 2010-2019 are used for robust testing; the spatial panel model is adopted The geographic distance matrix is tested for robustness, and the following results are obtained.

It can be seen from Table 3 that venture capital has a positive role in promoting green technological innovation and has a spatial effect. In addition, the research on the variable of government intervention level showed the same result. On the whole, the results of the robustness test are consistent with the results of this paper, which means that the test can be passed.

\section{Conclusions and Suggestions}

From the above analysis, the following conclusions can be drawn: 1) Venture capital has a significant positive impact on green technology innovation, and has a spatial effect, that is, the level of green technology innovation in the region will be affected by venture capital in surrounding areas. 2) The level of technological investment, the level of openness to the outside world and the intensity of environmental regulations all have a positive impact on green technology innovation. Each region can formulate policies based on its own conditions to improve the level of green technology innovation in the region. 3) The level of government intervention shows opposite effects in the regression of the ordinary panel model and the spatial panel model, and the conclusions of the spatial panel model are consistent, indicating that the ordinary panel model has estimation errors in this respect without considering the level of government intervention in surrounding areas, That is, the current level of Chinese government intervention has a certain squeezing effect on venture capital. 
Table 3. Results of robustness test.

\begin{tabular}{|c|c|c|c|c|}
\hline Variables & OLS & SAR & SEM & SDM \\
\hline $\mathrm{VC}$ & $\begin{array}{c}0.290^{* * *} \\
(0.000)\end{array}$ & $\begin{array}{c}0.126^{\star * *} \\
(0.008)\end{array}$ & $\begin{array}{c}0.123^{\star * *} \\
(0.009)\end{array}$ & $\begin{array}{l}0.102^{\star *} \\
(0.036)\end{array}$ \\
\hline $\mathrm{RD}$ & $\begin{array}{l}1.408^{\star * *} \\
(0.000)\end{array}$ & $\begin{array}{c}2.112^{\star * *} \\
(0.000)\end{array}$ & $\begin{array}{c}2.132^{\star * *} \\
(0.000)\end{array}$ & $\begin{array}{c}2.016^{* * *} \\
(0.000)\end{array}$ \\
\hline OPEN & $\begin{array}{c}0.117 \\
(0.270)\end{array}$ & $\begin{array}{c}0.187^{\star * *} \\
(0.000)\end{array}$ & $\begin{array}{c}0.184^{\star * *} \\
(0.000)\end{array}$ & $\begin{array}{c}0.242^{\star * *} \\
(0.000)\end{array}$ \\
\hline GOV & $\begin{array}{l}0.030^{\star *} \\
(0.043)\end{array}$ & $\begin{array}{l}-0.013 \\
(0.355)\end{array}$ & $\begin{array}{l}-0.013 \\
(0.384)\end{array}$ & $\begin{array}{l}-0.001 \\
(0.944)\end{array}$ \\
\hline EA & $\begin{array}{c}0.317^{\star * *} \\
(0.000)\end{array}$ & $\begin{array}{c}0.283^{\star * *} \\
(0.000)\end{array}$ & $\begin{array}{c}0.284^{\star * *} \\
(0.000)\end{array}$ & $\begin{array}{c}0.275^{\star * *} \\
(0.000)\end{array}$ \\
\hline $\mathrm{W}^{\star} \mathrm{VC}$ & & & & $\begin{array}{c}0.047 \\
(0.841)\end{array}$ \\
\hline $\mathrm{W}^{\star} \mathrm{RD}$ & & & & $\begin{array}{c}-2.040^{\star * *} \\
(0.003)\end{array}$ \\
\hline $\mathrm{W}^{\star} \mathrm{OPEN}$ & & & & $\begin{array}{c}0.938^{\star * *} \\
(0.002)\end{array}$ \\
\hline $\mathrm{W}^{\star} \mathrm{GOV}$ & & & & $\begin{array}{l}-0.065 \\
(0.455)\end{array}$ \\
\hline $\mathrm{W}^{\star} \mathrm{EA}$ & & & & $\begin{array}{l}-0.196 \\
(0.126)\end{array}$ \\
\hline Constant & $\begin{array}{l}-0.005 \\
(0.272)\end{array}$ & & & \\
\hline Lambda & & & $\begin{array}{c}0.189 \\
(0.136)\end{array}$ & \\
\hline rho & & $\begin{array}{c}0.029 \\
(0.789)\end{array}$ & & $\begin{array}{c}0.144 \\
(0.265)\end{array}$ \\
\hline sigma2_e & & $\begin{array}{c}0.000^{* * *} \\
(0.000)\end{array}$ & $\begin{array}{c}0.000^{\star * *} \\
(0.000)\end{array}$ & $\begin{array}{c}0.000^{* * *} \\
(0.000)\end{array}$ \\
\hline Observations & 300 & 570 & 570 & 570 \\
\hline R-squared & 0.503 & 0.536 & 0.540 & 0.521 \\
\hline F-test & 59.544 & & & \\
\hline Prob $>$ F & 0.000 & & & \\
\hline Log-likelihood & & 1352.7089 & 1353.7168 & 1361.3224 \\
\hline
\end{tabular}

Remarks: ${ }^{* *} \mathrm{p}<0.01,{ }^{* *} \mathrm{p}<0.05,{ }^{*} \mathrm{p}<0.1$.

According to the conclusion, the decision-making recommendations from the government's perspective are as follows: First, continue to expand the scale and main body of venture capital. The central government can reasonably formulate corresponding policies and guidelines to guide the rational flow of venture capital, eliminate the blindness of venture capital to a certain extent, for example, a 
foreign venture capital company with standardized operations shall be one of the initiators of a Sino-foreign joint venture capital company, and avoid the overheating of venture capital investment in a certain industry or a certain region, which leads to waste of manpower and material resources. Second, increase the level of technology investment. At present, China's internal R \& D expenditures account for a relatively low proportion of GDP, with an average of less than $2 \%$, which is quite different from developed countries. Therefore, it is necessary to continue to increase the scale of technology investment, support the development of strategic green technological innovation industries, and release industrial dividends in advance. Improve the independent ability of green technology innovation, further accelerate the process of industrial ecologicalization, and reserve more reserve technologies. Third, rationally formulate various development policies. Such as providing government guarantees for venture capital financing; allowing pension funds and insurance companies to moderately participate in venture capital; preferential taxation policy. When formulating corresponding development policies, governments at all levels in China need to focus on matching and coordinating with other policies, so as to leverage the spillover effect of venture capital on green technology innovation. Maintain a unified level to play the role of environmental regulations.

The limitations of the research are as follows: on the one hand, data from various regions of China from 2001 to 2019 to analyze the relationship between China's venture capital and green technology innovation, failed to retrieve data from 2020 to 2021; on the other hand, we are studying Chinese samples, but have not been able to research international samples. In the future, the research can be extended to samples from the United States, the United Kingdom, Europe and other regions.

\section{Conflicts of Interest}

The authors declare no conflicts of interest.

\section{References}

[1] Lerner, J. (2000) Assessing the Contribution of Venture Capital. The RAND Journal of Economics, 31, 674-692.

[2] Tykvova, T. (2000) Venture Capital in Germany and Its Impact on Innovation. Social Science Research Network, 1-30.

[3] Pradhan, R.P., Maradana, R.P., Zaki, D.B., et al. (2017) Venture Capital and Innovation: Evidence from European Economic Area Countries. International Journal of Innovation and Technology Management, 14, Article ID: 1750031. https://doi.org/10.1142/S0219877017500316

[4] Sun, W., Zhao, Y. and Sun, L. (2020) Big Data Analytics for Venture Capital Application: Towards Innovation Performance Improvement. International Journal of Information Management, 50, 557-565. https://doi.org/10.1016/j.ijinfomgt.2018.11.017

[5] Yan, F., Chen, J.R. and Tao, L. (2016) Venture Capital, R \& D Investment and Technology Innovation: An Empirical Study Based on Co-Integration and VECM Mod- 
el. Modern Business Trade Industry, 37, 3-6.

[6] Wang, X.X. (2021) Venture Capital, R\&D Investment and China’s Green Technology Innovation. Industrial Technology Economy, 40, 23-27.

[7] Chen, Z. (2010) China's Regional Venture Capital Research on the Role of Technological Innovation. Ph.D. Thesis, Shanxi University of Finance and Economics, Taiyuan, China.

[8] Xu, D.T. (2016) Venture Capital, Government Investment in Science and Technology and Technological Innovation. Master's Thesis, Chongqing University, Chongqing, China.

[9] Yao, L. (2018) Venture Capital, Regional Technological Innovation Level and Spatial Effect: An Empirical Study Based on Provincial Spatial Panel Data. Contemporary Economic Management, 40, 7-12.

[10] Wen, J., Yang, D., Feng, G.F., et al. (2018) Venture Capital and Innovation in China: The Non-Linear Evidence. Structural Change and Economic Dynamics, 46, 148-162. https://doi.org/10.1016/j.strueco.2018.05.004

[11] Zhang, Y.K. and Wang, J.J. (2019) The Impact of Venture Capital on China's Regional Innovation Capability. Development Research, 1-8.

[12] Liu, C.Y., Gao, X.Y., Ma, W.L., et al. (2020) Research on Regional Differences and Influencing Factors of Green Technology Innovation Efficiency of China's HighTech Industry. Journal of Computational and Applied Mathematics, 369, Article ID: 112597. https://doi.org/10.1016/j.cam.2019.112597

[13] Wang, Q.H., Qu, J.S., Wang, B., et al. (2019) Green Technology Innovation Development in China in 1990-2015. Science of the Total Environment, 696, Article ID: 134008. https://doi.org/10.1016/j.scitotenv.2019.134008

[14] Cheng, D. and Li, G. (2017) Current Situation and Trend of Environmental Regulation Intensity Measurement. Economic and Management Research, 38, 75-85.

[15] Jiang, H.M. (2019) Knowledge Spillover, Informatization Level and Technological Innovation Capability of FDI. Journal of Jiangxi University of Finance and Economics, 34-42.

[16] Qiao, Q., Fan, J., Sun, Y., Liu, B.Y. and Liu, H.C. (2021) Study on the Spatial and Temporal Distribution of Venture Capital in China's "the Belt and Road Initiative" Region and Its Influencing Factors. Science and Technology Progress and Countermeasures, 38, 37-45. 